\title{
Research on the Strategy of Implementing the Blended Teaching Model in College English Teaching
}

\author{
Xinfa Sun \\ College of Liberal Arts, Xi'an International University,Xi'an Shaanxi 710077
}

Keywords: College English, Teaching Model, Blended Teaching Model, Strategy.

\begin{abstract}
As the construction of the MOOCs, the blended teaching model, and all kinds of teaching platforms, and as the innovation of all kinds of teaching methods, the blended teaching model has gradually come into view. By the influence of the reform of the system in China, the domestic education is optimizing and updating step by step; in the new environment of the new curricular reformation, how to innovate the teaching model and keep up with the times, and how to improve the traditional teaching model so as to enhance the English quality of the teachers and their students are the very questions that the college English teachers must think a lot. According to the current situation, to improve the teaching quality of English by simple teaching method is infeasible. Therefore, in the current important period of reformation, it is urgent to reform the English teaching model in class. How to use the new teaching thoughts to construct the scientific and efficient teaching model, and then to introduce many new teaching methods into teaching activities and take the best of the blended teaching model is the question that every people who dedicates themselves to education business should face and solve in the new environment. The emergence of the blended teaching model is the important milestone of the teaching model; it is a kind of reform, innovation, and subversion to the traditional teaching model. The writer of this thesis starts this thesis from the connotation of the blended teaching model in college English class, and then discusses the application of the blended teaching model in college English teaching.
\end{abstract}

\section{Introduction}

The traditional teaching model of English should be improved in the new teaching environment, it is necessary to follow the colleges' current developmental situation of teaching. In order to decrease the limitations of the traditional teaching model, and to let the students make great progress, and to improve their comprehensive abilities and studying efficiencies, it is necessary to implement the new teaching model----online course. The implementation of English online course is not only a kind of reflection of the innovation in class, but also a important way to increase the students' studying interest and to improve the teaching abilities and teaching efficient of the teachers.

\section{Conception of the blended teaching model}

In "Blended Learning", the word "Blended" means "mix" or "combination", it has been translated into many Chinese expressions as below: "comprehensive learning”, "mixed learning”, "blended learning model", or "learning by different methods", all the expression above have the meaning ---- the combination of all the teaching methods ${ }^{[1]}$. The word "Blended Teaching", it emergences in late 1990s, in that time, online education by computer becomes popular and it starts its development, and people like it very much because of its advantages such as it could concentrate the merits of many teachers; it could share lots of online teaching resources and use all the functions of the internet. But, because of the futures of this teaching model and some factors which is caused by people, it appears some defects, for example, it emphasizes self-study too much so that the leading action of the teacher becomes weak; it emphasizes that the teachers should teach the relevant knowledge to the students but neglects following and assessing to the whole teaching 
activities, etc. Therefore, the educational circle begins to rethink these popular teaching theories and its application in online education reasonably, and finds out that only these problems have been solved the online education could play its function totally. The blended teaching model was put forward once more under this background. What's more, the mode was given a new connotation that is blended learning, i.e. blended E-learning which the educational circle has paid attention to it, and has tried to adopt it and discussed it ${ }^{[2]}$.

\section{Necessity of the using the blended teaching model in college English class.}

As the development of the reform on college English teaching, the goal and the position of college English have been clarified. So, it is very important to reform the present teaching model of the college. To adopt the blended teaching method, to enhance the students' studying and applying abilities of English, these have great realistic significance ${ }^{[3]}$. What's more, the blended teaching model could change the simple traditional teaching model that the teachers are the most important part and they teach their students rigidly; it also pays more attention to the students, and takes the

students as the most important part ${ }^{[2]}$. Classroom is the place where education is implemented, and the students are the people who receive the lessons. The features of the blended teaching are innovation, efficient, easily to participate, and diversified teaching methods. It is a kind of teaching model that is full of creativity. The teachers should adopt the appropriate teaching method after the assessment to the students' comprehensive abilities such as the accomplishing rate of the schedule, and their studying abilities and so on; the teacher also should seek the truth from facts and keep up with the times, and choose the feasible teaching model that could fulfill the realistic requirement, so as to enrich their personal ability. In addition, the blended teaching model could enrich the English lessons by the massive online resources, and it broadens the students' scope of knowledge and improves the teaching quality. To teach English by the online resources and online platforms, it could not only increase the flexibility of English teaching, but also increase the specialty and functionality of English teaching. To popularize the blended teaching model, to adopt the different teaching methods to deal with the different teaching goals of the different phases, and to teach the different courses by the different teaching methods, these could enhance the pertinence of the course, and improve their teaching ability and teaching efficiency.

\section{The current situation and problems of college English teaching}

At present, many English teachers still follow the traditional teaching model that repeats what the books say, and their teaching models are rigid without creativity so that the college English lessons are lack of vitality; these are the important reasons that many students lose their interests in English learning. It is tedious in class, the teaching model is simple, and the teachers are not interest in the application of the new teaching equipments and the new teaching methods such as the MOOCs, the online course, and the blackboard etc so that it blocks the improvement of the teachers' teaching abilities ${ }^{[4]}$.

There are not enough effective teaching methods that could let the students like to learn English is the main reason that influences the efficiency of college English study, so the students are not diligent in English study. The English teaching involves massive words, grammars, it is very tedious, if the teaching method would not be innovated, and the teaching and learning results must be weakened.

\section{The strategy of implementing the blended teaching model in the college English teaching.}

The blended teaching model emphasizes the feeling of the students; it launches the teaching activities by taking the students as the most important part. The teaching without communication likes a body without the soul; it must be far away from the expected teaching goals. The teaching without communication, all the conclusions and suspicions are lack of scientific basis; only by communication could the teachers understand the thoughts of the students, could the teachers 
choose the proper teaching method according to the specific circumstance and achieve a good teaching result by using the blended teaching method. The teachers should give the students some advices actively, and play their roles as a guider in teaching so as to achieve the expected result that the teachers and the students could communicate with each other freely, the teachers could know the studying situation of the students, and the students could understand the teaching contents of the teachers. The teachers should adopt or adjust the proper teaching methods according to the feedback of the students; only by this could the advantage of blended teaching work.

As the guider in class, the teacher is not only the organizer and guider in class, but also the partner of their students. Because the teachers understand the importance of improving the efficiency of English learning, so the teacher's personal teaching model is very important. Only to combine various teaching model together could the advantage of the blended teaching work. The teachers must change the teaching model that repeats what the books say and aims for examination, and make their lessons lively by means of below. First, the teachers could use some electronic equipments such as computer, project camera etc. to attract the students' attentions. The teachers also could use some video resources to increase the students' interests. Second, the teachers could adopt some new teaching methods properly, such as the flipped class model, the MOOCs, and E-learning, to increase the students' learning interests so as to fulfill the aim of improving the teaching quality. Only to adopt some different teaching models, the advantage of the blended teaching model could work; only to seek the truth from facts and to make a breakthrough by innovation, the effective English class could be established.

The teachers' teaching abilities and their English abilities determine the results of their students' English learning and the training result of the students' thinking mode of English. The teachers must have strong abilities of innovation, have strong courage and determination to accept the new things such as the MOOCs, online course, and the blackboard etc, and have the enough abilities that push the online study forward and filter the online resources ${ }^{[7]}$. The blended teaching model could not be carried out without the teachers' overall control. Only the teachers have a deep understanding about the blended teaching model and make a reasonable plan and arrangement could the advantages of this model be brought into play. Therefore, the English teachers should consider the real condition of their own and improve their comprehensive abilities so as to ensure the teaching quality and teaching efficiency. The English teachers must keep their teaching abilities at a high level by their profound knowledge reservation and the scientific teaching methods, and teach their students all heart and soul. At the some time, the students could not only learn English effectively, but also improve their thinking mode of English by the guidance of their teachers.

\section{Conclusion}

To college English teaching, it is necessary to change the simple teaching method and to adopt the blended teaching method and use the new teaching model in the new times. Especially, to the college English teacher, it is also necessary to change the traditional teaching model and to adopt the new teaching methods, to combine the teaching with the modern technologies, and to use the advanced teaching model which depends on the online teaching resources, and then to build a new teaching model which is much more suitable to the students. To introduce the blended teaching model to English teaching is not only the requirement of the developmental times, but also an important way of improving the efficiency in class. To the students, it increases their learning interests, gives them lots of inspirations, and improves their learning efficiencies. By summarizing some experiences in the actual teaching activities, the writer of this thesis hopes this thesis could provide some helps to the theory of English teaching. Because of the limited knowledge, the writer's view on this issue is not overall. Welcome more and more scholars to join us and make a further discussion. 


\section{References}

[1] Zhang Mulin, Sun Xiaojun, Research on the Blended Teaching Model Base on the MOOCs [J]. Modelrn Educational Technology, 2015,25(08):81-87.

[2] Li Xia. Research on the Experiment that the Application of the Blended Teaching Method In the Colleges' Distanced Listening Learning Via the IC3 Teaching Platform[J]. Journal of Shandong Radio and TV University, 2015, (04):50-52.

[3]Li Ruili, Hu Minghuan. Discuss On the Blended Teaching Model of College English Teaching In Internet Environment[J]. Modelrn Electronics Technique, 2006,(16):94-96+99.

[4] Qi Hong, Fu Zhuqin. Empirical Research On the Blended Teaching Model of College English Teaching Via the Blackboard Platform[J]. Journal of Xi'an International Studies University, 2007,(03):84-87.

[5] Zhang Yan. The Direction and Ways of the Reform on College English Teaching in Internet Times[J]. Journal of Jiangsu Normal University (Philosophy and Social Sciences Edition), 2015,41(06):142-146.

[6] Feng Fei, Liu Sa, Wang Ying, Chen Fei, Tong Xiaoping, Wang Qiong. Study of the Next Generation: Wish, Innovation, and Possibility----Report of the $7^{\text {th }}$ Asian Digital Learning Congress[J]. Journal of Distance Education, 2012, 30(04):3-19.

[7] Ma Wulin, Jiang Yan. Analysis on the Problems of Listening English Learning of the College Students Whose Major Is Not English and the Causes of These Problems[J]. Overseas English, 2013, 29(01):138-143. 